\title{
The Effects of Serotonin and Ecdysone on Primary Sensory Neurons in Crayfish
}

\author{
ROBIN L. COOPER, ${ }^{1 *}$ ELIZABETH WARD,${ }^{1}$ RECENNAH BRAXTON,${ }^{2}$ HAO LI,${ }^{1}$ AND WENDY M. WARREN ${ }^{1}$ \\ ${ }^{1}$ Thomas Hunt Morgan School of Biological Sciences, University of Kentucky, Lexington, Kentucky 40506-0225 \\ ${ }^{2}$ Talladega College, Division of Natural Sciences and Mathematics Talladega, Alabama 35160
}

\begin{abstract}
KEY WORDS proprioception; serotonin; ecdysone; crustacean; neuromodulation
\end{abstract}
\begin{abstract}
The overall behaviors and motivational states observed during social interactions and throughout the molting cycle of crayfish have been linked to the effects of humoral neuromodulators. Both serotonin (5-HT) and a molt-related hormone, 20-hydroxyecdysone (20-HE), are known to be present in the hemolymph of crustaceans. To determine if they alter the activity of a primary sensory neuron that monitors proprioceptive information, we examined their effects on the activity of the slow-adapting muscle receptor organ (MRO) of the crayfish abdomen, a model sensory system that has been extensively studied. 5-HT within the range of $100 \mathrm{nM}$ to $1 \mu \mathrm{M}$, increases the firing frequency of the neuron during sustained stimulation. In experiments in which 20-HE was added alone, an increase in the firing frequency also occurred, although to a lesser degree than that for 5 -HT at the same concentrations. When the MRO is first exposed to 20-HE, followed sequentially by 5 -HT, the activity increases to about the same degree as in the reverse order of exposure. This outcome indicates that mixtures of these endogenous neuromodulators, at various levels, are more important in alternating behavior than the absolute level of any one of them introduced alone. Microsc. Res. Tech. 60:336-345, $2003 . \quad$ ๑ 2003 Wiley-Liss, Inc.
\end{abstract}

\section{INTRODUCTION}

Neuromodulators are substances typically released by neuroendocrine cells into general circulation or near the specific cell that they modulate. They usually act by affecting the biophysical properties of the neuron's cell membrane, which leads to alterations in the amount of neurotransmitter substance that is released from the presynaptic neuron and/or the responsiveness of the cell to a transmitter and/or electrical excitability. One neuromodulator that has been found to modify the behavior of a wide variety of animals from crustaceans to mammals is serotonin (5-HT) (Cases et al., 1995; Coccaro, 1992; Guillemin, 1978; Huber et al., 1997a,b; Jan and Jan, 1982; Kravitz et al., 1980; Linnoila and Virkkunen, 1992; O'Shea and Schaffer, 1986; Winberg et al., 1992). Earlier investigations with lobsters and crayfish (Huber et al., 1997a,b; Huber and Delago, 1998; Livingstone et al., 1980) as well as crabs (Sneddon et al., 2000) suggested that high levels of 5-HT produce dominant, aggressive patterns of behavior. However, recent work (Doernberg et al., 2001) suggests that serotonin might not be the key substance; possibly there are other endogenous compounds that regulate aggression. Current studies imply that varied responses in neuronal function arise due to mixtures of endogenous neuromodulators and not absolute levels (Djokaj et al., 2001).

Ecdysone is another widespread neuromodulator that is believed to play a role in modulating behavior in lobsters during the molt cycle (Cromarty et al., 1998) and also is known to alter neuronal activity. The active form of ecdysone (20-Hydroxyecdysone, 20-HE) is a steroid molecule and has been shown to have nongenomic (Von Richter, 1979; Ruffner et al., 1999) and genomic (Segraves, 1994) actions on neurons of insects.
At the crayfish neuromuscular junction, 20-HE was shown to decrease transmitter release (Cooper and Ruffner, 1998). Crustaceans, like insects, show quiescence at times in the molt cycle when 20-HE titers are high.

The effects of 5-HT and 20-HE on primary sensory neurons have only briefly been addressed in the literature. No reports to date have appeared on the effects of 20-HE in relation to non-genomic, rapid influences on invertebrate sensory systems. To determine the effects of 5-HT and 20-HE on an identified sensory cell neuron, we chose to use the abdominal proprioceptive sensory system of crayfish, referred to as the muscle receptor organs (MROs), which monitor the positions and movements of the abdominal segments (Eckert, 1961a,b; McCarthy and MacMillan, 1995). This mechanoreceptor transduces the stimulus of stretch of the sensory endings into a receptor potential that is conducted past the cell body. If this potential exceeds a threshold, an action potential will result at the axon base.

The neuron cell body is located in close proximity to the muscle it monitors. Two distinct types of stretch receptors exist in this sensory system: a slowly-adapt-

\footnotetext{
*Correspondence to: Dr. Robin L. Cooper, Thomas Hunt Morgan School of Biological Sciences, University of Kentucky, Lexington, KY 40506-0225.

E-mail: RLCOOP1@POP.UKY.EDU

Received 9 February 2001; accepted in revised form 8 November 2001

Grant sponsor: Howard Hughes Medical Institute; Grant sponsor: NIH; Grant number: NIGMS-GM 55275; Grant sponsor: NSF; Grant numbers: IBN-9808631 and ILI DUE-9850907.

E. Ward, R. Braxton, and W.M. Warren are undergraduate students; H. Li is a $\mathrm{PhD}$ graduate student.

DOI 10.1002/jemt.10272

Published online in Wiley InterScience (www.interscience.wiley.com).
} 
ing and a rapidly-adapting receptor. The activity pattern of the slowly-adapting MRO is dependent on the strength of the mechanical stretch. This MRO system in the crayfish is analogous to the intrafusal muscle spindle in mammals. However, the muscle spindle organs in vertebrates are challenging to investigate electrophysiologically, whereas the sensory neurons of the MRO are easily accessible to extracellular and intracellular electrodes for long term recordings. The cell bodies of the sensory neurons are relatively large (50$100 \mu \mathrm{m}$ in diameter) and not contained in a ganglion as in vertebrates. The excised preparation also allows easy application and access of various neuromodulators to the neurons to examine potential effects. The natural flexion of the segments within the intact crayfish abdomen can be mimicked in an excised preparation examined in a dish containing a physiological saline.

The MRO of the crayfish is a model sensory system that has been extensively studied for its basic properties since its description in lobsters by Alexandrowicz in 1951 (Alexandrowicz, 1951; Eckert, 1961a,b; Kuffler, 1954; Nakajima and Onodera, 1969a,b; Nakajima and Takahashi, 1966; see reviews by Bush and Laverack, 1982; Fields, 1976; Swerup and Rydqvist, 1992). The anatomical arrangement within the animal is well described (Florey and Florey, 1955) and the excitatory and inhibitory innervation of the muscle spindle as well as the efferent input on the neurons themselves are known (Elekes and Florey, 1987a,b; Eyzaguirre and Kuffler, 1955; Kuffler and Eyzaguirre, 1955). This preparation has also provided an understanding of sensory transduction by the activation of "stretch activated" channels in neurons (Erxleben, 1989). In addition, voltage-clamp and patch-clamp studies of the neuronal membrane have provided a fundamental understanding of ionic flow, channel distribution, and density, as well as regional properties of sensory neurons (Brown et al., 1978; Edwards et al., 1981; Erxleben, 1989; Hunt et al., 1978; Purali and Rydqvist, 1992; Rydqvist and Purali, 1991; Rydqvist and Swerup, 1991).

From these past studies, the localized region termed the "site of spike initiation" was identified, which is related to a region of reduced threshold to activation. The early work of Eckert (1961a,b) had illustrated that activation of the MRO in one abdominal segment can influence the activity of primary sensory neurons in an adjoining segment. This revealed processing within the segmental ganglion and influence of efferent control within the ventral nerve cord.

Pasztor and Macmillan (1990) examined the neuromodulators 5-HT and octopamine on the activity of MROs among various crustacean species. They measured the spike frequency during pulls of 0.25 - to 1.25second durations, and showed that the activity was enhanced in the presence of the neuromodulators, and that the degree of change was dependent on the crustacean species. They did not examine in detail the long-term influences of these neuromodulators nor the effects on activity at different static positions of the MRO.

We chose to examine both the chronic and the acute effects of 5-HT and 20-HE upon this primary sensory neuron by examining the changes in firing frequency in response to a static stretch, characteristic of the relatively inactive periods of movement observed for crayfish in their natural settings. We were also interested to know if the effects of the neuromodulators are dependent on the state of firing activity of the cell. These two points are fundamental to understanding sensory physiology and have not been well addressed in mammalian or in invertebrate systems.

Preliminary findings were reported previously in abstract form (Li et al., 1997).

\section{MATERIALS AND METHODS Preparation}

Male crayfish (Procambarus clarkii), measuring 6-10 cm in body length, were used throughout this study (Atchafalaya Biological Supply Co., Raceland, LA). They were housed individually in indoor tanks. Temperature and exposure to light (full spectra lights, General Electric; on a 16-hour light:8-hour dark cycle) were kept constant. They were fed dry pellet fish food supplemented by carrots.

The muscle receptor organs of the crayfish were exposed by cutting the shell along the lower lateral border of the abdomen on each side, along the series of small indentations. The shell was separated into two parts: a dorsal section and a ventral section. The ventral half was discarded. The deep abdominal extensor musculature was comprised of a relatively small mass of muscle attached along the upper half of the shell. The preparation was anchored to a Sylgard-coated dish with the ventral view, or muscle-side-up.

Each abdominal segment has two sets of the rapidlyand slowly-adapting MROs on the right and left hemisegments. The associated nerve bundles run along the lateral edge next to the cuticle. The deep extensor medial muscle (DEM), with fibers twisted in a helix, and a deep extensor lateral muscle (subdivided into $\mathrm{DEL}_{1}$ and $\mathrm{DEL}_{2}$ ), with linear fibers, can be distinguished. Underneath the deep extensor muscles are the smaller superficial extensor muscles, which are fully revealed only by dissecting away the $\mathrm{DEL}_{1}$ and $\mathrm{DEL}_{2}$ muscles (Fig. 1). The nomenclature of these muscles follows the work of Sohn et al. (2000). Both the phasic and tonic receptor muscles of the MRO were left attached to the cuticle. The cuticle was pinned to a 3-ml Sylgard-coated dish. The segments, spanning the joint of interest, were pinned varying distances apart. The only muscles left attached to the cuticle, spanning the segment of interest, were the muscles associated with the MROs.

Neuromodulators were applied by completely exchanging the bathing medium using pipettes. One pipette was used to withdraw solution while a second one was used to add new bathing medium. However, during the exchange of bathing solutions, which usually took less than 30 seconds, the electrical noise level increased to $60 \mathrm{~Hz}$, which in some cases precluded measurements of the firing frequency during this time.

Dissected preparations were maintained in crayfish saline, a modified Van Harreveld's solution (in $\mathrm{mM}$ : $205 \mathrm{NaCl} ; 5.3 \mathrm{KCl} ; 13.5 \mathrm{CaCl}_{2} 2 \mathrm{H}_{2} 0 ; 2.45 \mathrm{MgCl}_{2} 6 \mathrm{H}_{2} 0$; 0.5 HEPES adjusted to pH 7.4). All bathing and experimental solutions were kept at the experimental room temperature of $20^{\circ} \mathrm{C}$. 


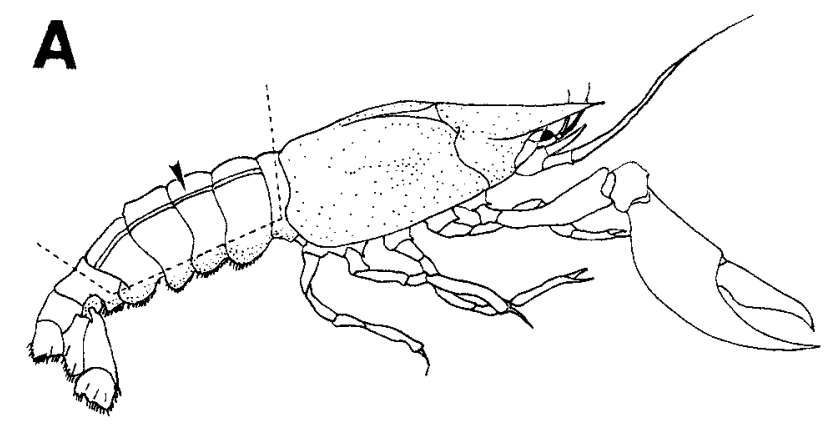

B
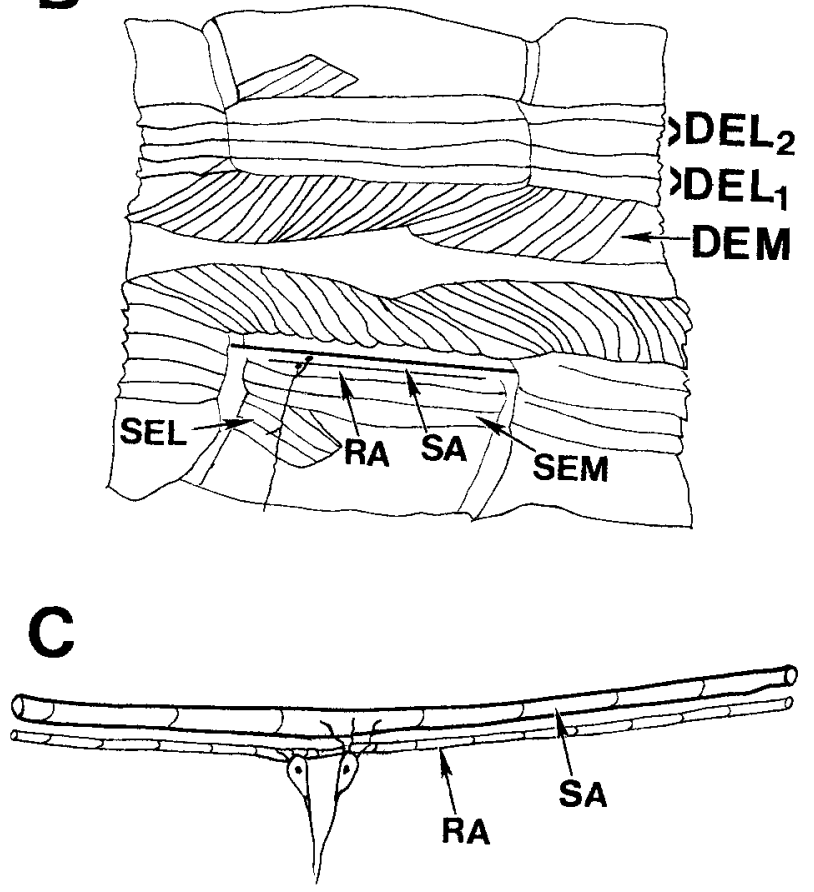

Fig. 1. The layout of the muscle receptor organs (MROs) in relation to the superficial and deep extensor muscles of the crayfish abdomen. A: The MROs are located on the dorsal aspect of the abdomen and monitor the position and movements of the abdominal segments. B: A schematic of the superficial and deep extensor muscles with the particular muscles identified. The most deep extensor medial (DEM) muscles have a spiral fiber pattern. In the top half, the deep extensors muscles are shown. $\mathrm{DEL}_{1}$ is the first lateral group followed by the $\mathrm{DEL}_{2}$ muscles. In the bottom half, the $\mathrm{DEL}_{1}$ and $\mathrm{DEL}_{2}$ musculature was removed to show the more dorsal superficial extensor muscles. The superficial extensor medial muscle (SEM) lies directly dorsal to $\mathrm{DEL}_{1}$ and $\mathrm{DEL}_{2}$. The most lateral bundle of fibers is the superficial extensor lateral muscle (SEL). The two MRO muscles are just medial to the SEM muscle. C: The anatomical arrangement of the rapidly-adapting (RA) and slowly-adapting (SA) sensory neurons to the muscle fibers which they monitor (after Purali, 1997). The motor innervation is not shown.

\section{Neuromodulators}

A solution of 20-HE (Sigma, St. Louis, MO) was freshly made prior to experimentation. Serotonin (Sigma; 5-HT.HCl) was diluted from a frozen stock $(1 \mathrm{mM})$ on the day of use. Standard concentrations used were $10^{-8}, 10^{-7}$, and $10^{-6} \mathrm{M}$ for 5 - HT and $10^{-8}, 10^{-7}$, and $10^{-5} \mathrm{M}$ for 20 -HE. The $10^{-5} \mathrm{M}$ of 20 -HE was used to compare to neuronal response of the opener excitatory motor nerve terminal (Cooper and Ruffner, 1998). Both solutions were stored in the dark until used. When the solutions were placed in the recording chamber, the microscope lights were turned off, and the room lighting blocked by using drapes around the Faraday cage.

\section{Electrophysiology}

Suction electrodes made from glass pipettes fitted with plastic tips were used to record extracelluar signals from the cut nerves. Recordings were made selectively from the slowly-adapting neurons by transecting the nerve segment that was associated with the rapidly-adapting MRO. In all experimental trials, the pull stimuli consisted of a long-term static stretch by pinning the preparation in place.

Intracellular electrodes had a resistance on the order of 20 to $40 \mathrm{M} \Omega$ and were filled with $3 \mathrm{M} \mathrm{KCl}$. The extracellular signals were amplified via a P-15 (Grass Instr.), and intracellular signals by an Axoclamp 2B (Axon Instr.). A MacLab (4s), in conjunction with a Power Mac 9500, were used for data acquisition at $10 \mathrm{kHz}$ on line. MacLab chart software was used for offline analysis of firing frequency.

The percent change in the firing frequency potentially induced by modulators was determined by a percent difference as compared to the average firing frequency prior to the exposure of the compounds (i.e., in saline only) by the following manner:

\section{( | activity in saline-activity while exposed to modulator $\mid$ ) activity in saline $\times 100=\%$ Difference. \\ RESULTS \\ 5-HT and 20-HE Influences on Activity}

In this study, we investigated the role of two neuromodulators on the activity of the slowly-adapting MRO. Since both 5-HT and 20-HE are known to be present in the hemolymph of crustaceans (Cooke and Sullivan, 1982) and cause alterations in behavior, these two compounds were used. It is thought that the 5 -HT levels vary depending on social status in crustaceans, and it is known that 20 -HE varies over the molt cycle, but no attention has been previously given to the possible influences of these two modulators on primary sensory activity.

To maintain uniformity in the animals to be compared, the animals used were held in isolation for 2 weeks, in separate containers, under the same conditions. A typical activity profile of a slowly-adapting MRO is shown in Figure $2 \mathrm{~A}_{1}$ while it is bathed in saline. Upon exchanging the bathing medium to saline containing $100 \mathrm{nM} 5-\mathrm{HT}$ or $10 \mu \mathrm{M} 20-\mathrm{HE}$, the firing frequency increases (Fig. $2 \mathrm{~A}_{1}$ and $\mathrm{B}_{1}$ ). Plots of instantaneous frequency profiles revealed surges in the activity upon contact with the 5-HT containing saline (Fig. $2 \mathrm{~A}_{2}$ ) and 20 -HE (Fig. $2 \mathrm{~B}_{2}$ ). An average firing frequency, monitored every 10 seconds is shown in Figure $2 \mathrm{~A}_{3}$ and $\mathrm{B}_{3}$ for the responses to 5-HT and 20-HE, respectively.

To control for the mechanical disturbance induced by switching the bathing medium in the preparation dish, sham experiments were conducted in which the original bathing saline was replaced by fresh saline. The 
$\mathbf{A}_{1}$

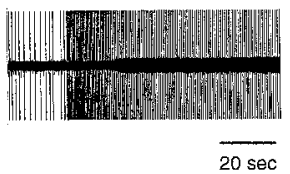

$A_{2}$
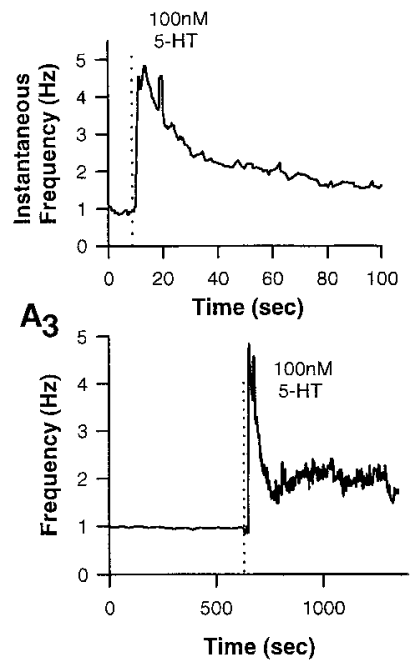

$\mathbf{B}_{1}$

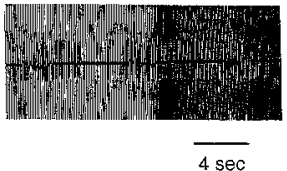

$\mathrm{B}_{2}$

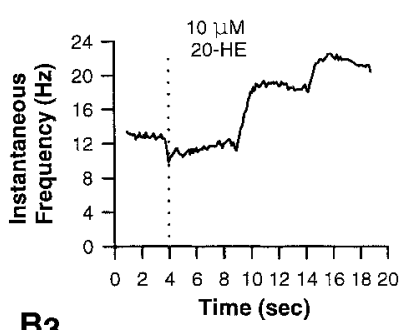

B3

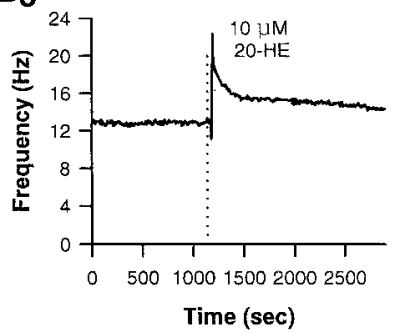

A

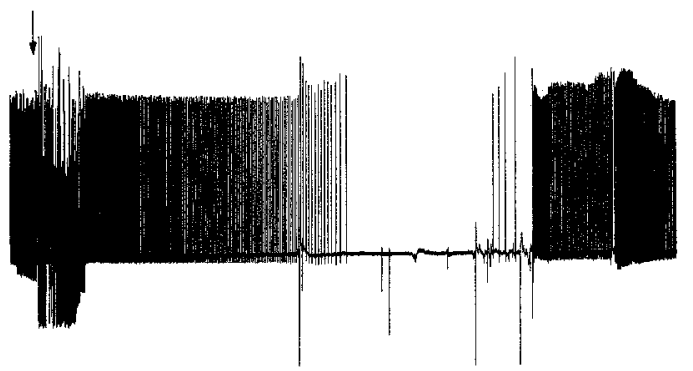

B

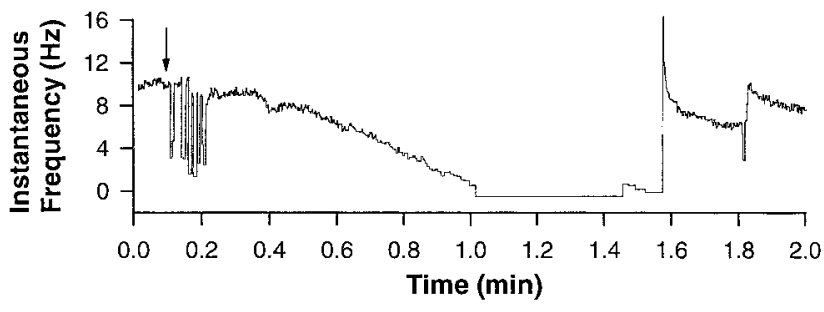

C

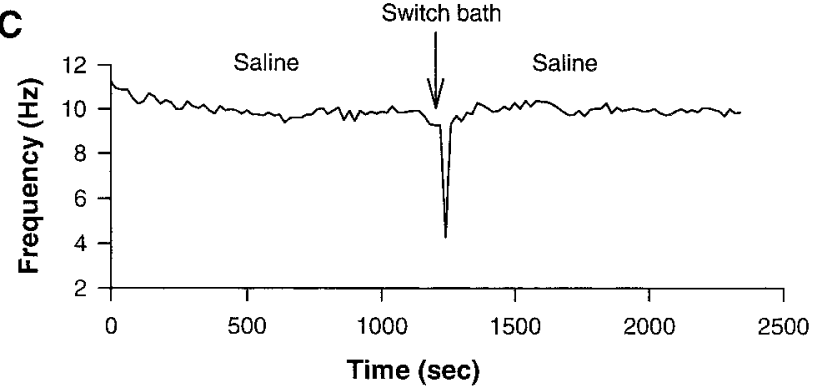

Fig. 3. The effect of switching the bathing medium. Control experiments of replacing the saline bathing medium with new saline medium were performed. These sham experiments indicated that during the period of switching the medium, some preparations produce short (0.5-second) bursts of increased firing frequency. In 3 out of the 5 of these experiments, there was a decrease in the firing frequency for a few seconds following the bath exchange. The raw trace of the recorded spikes (A) and instantaneous frequency response (B) show these alterations clearly during and after bath exchange. The arrows in $\mathrm{A}$ and $\mathrm{B}$ indicate the start in switching the bathing media. The compressed time scale, of several minutes, also reveals the temporary decrease $(\mathbf{C})$ but it is also apparent that the basal rate is maintained for prolonged periods of time.

nate the responses during the long-term measures for neuromodulators effects on altered activity (Fig. 3C). The plots of the average responses, taken at 10-second intervals, allowed a manageable overview of the activity for prolonged periods of time during the control experiments as well as during exposure to the modulators.

Response times for 5-HT (100 nM) and 20-HE $(10 \mu \mathrm{M})$ were different in their initial effects and over sustained periods of time while the MRO strand was maintained in a static position. We do not know how to account for these differences. Perhaps the animals were in different phases of the intermolt cycle, but their history is unknown. However, we do know that the animals were not close to the act of molting nor had they just finished a molt within a 2 -week period.

A maximum increase in the firing frequency was observed within the first minute, and it decreased over time while the preparation was maintained in the presperiod reveal no prolonged effects that could contami- 

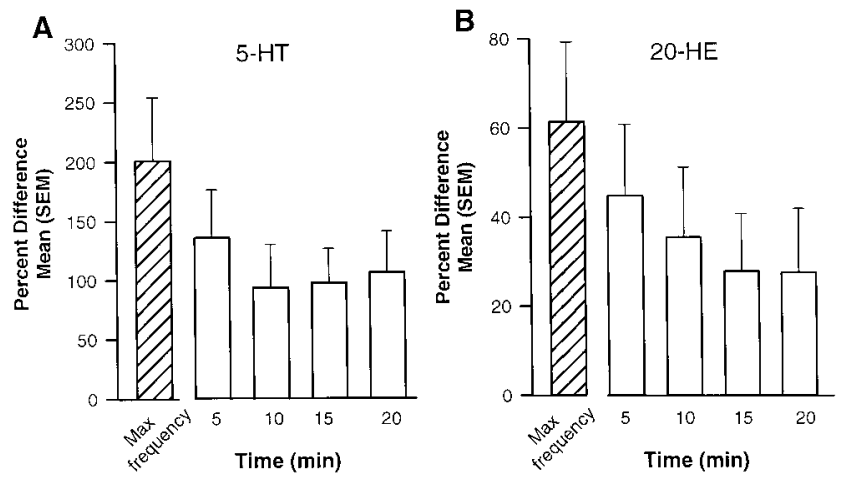

Fig. 4. The onset and decay of 5-HT and 20-HE effects on the firing frequency. Both 5-HT (A) and 20-HE (B) showed their greatest effect on the activity within the first minute of exposure with a gradual decay in the heightened activity over the next 20 minutes. The percent differences in the increased firing frequency for 20-HE was always less than that of 5-HT at the same concentrations. The percent difference comparison in firing frequency is to an averaged baseline value over several minutes prior to exchanging the bathing medium. The mean values of the percent difference are from five preparations and the error bars represent standard errors from the mean.

ence of 5-HT (Fig. 4A). The time course for the excitatory effect of $20-\mathrm{HE}$ looked much like that for 5-HT with the exception that the response times and decay were more varied among preparations (Fig. 4B). The decay of the 20-HE-induced increase in the firing frequency was gradual for the majority of the preparations.

To determine whether or not the neuromodulator's actions were dependent on the initial firing frequency, the initial firing rate in saline was plotted against the percent difference at 5 and 20 minutes for 5 -HT or 20-HE exposures separately (Fig. 5). There was less difference in the firing frequency after 20 minutes than at 5 minutes for both the isolated 5-HT and the 20-HE exposures. The higher the initial rate of electrical activity, the smaller the change in activity upon exposure of the neuromodulators. This sensory receptor's dependence on the rate of activity is similar to that shown for 5 -HT in modulating a type of rhythmic motor activity in crustaceans (Nusbaum and Marder, 1989).

\section{Interactions of 5-HT and 20-HE}

Prior to molting in insects and crustaceans, there is selective muscle (Moffet, 1975; Truman and Reiss, 1995) and cuticular degradation (Cameron, 1989), which allows the animal to carry out the molt. These physiological changes may account for behaviors associated with molting. For example, the crab, Cancer magister, will tend to remain buried in sand prior to the molt and remain relatively inactive in laboratory conditions (Cooper and Hartman, personal observations). Previous studies examined the roles of $20-\mathrm{HE}$ and 5-HT at the neuromuscular junctions of crayfish (Cooper and Ruffner, 1998) that might possibly account for such behavioral responses. In this present study, we show that the excitatory actions of 5-HT can still occur with prior exposure to 20-HE (Fig. 6A), and likewise, the excitatory actions of 5-HT can be further increased by the addition of $20-\mathrm{HE}$ (Fig. $6 \mathrm{~B}$ ). When the two modulators are exposed to the preparation simultaneously,
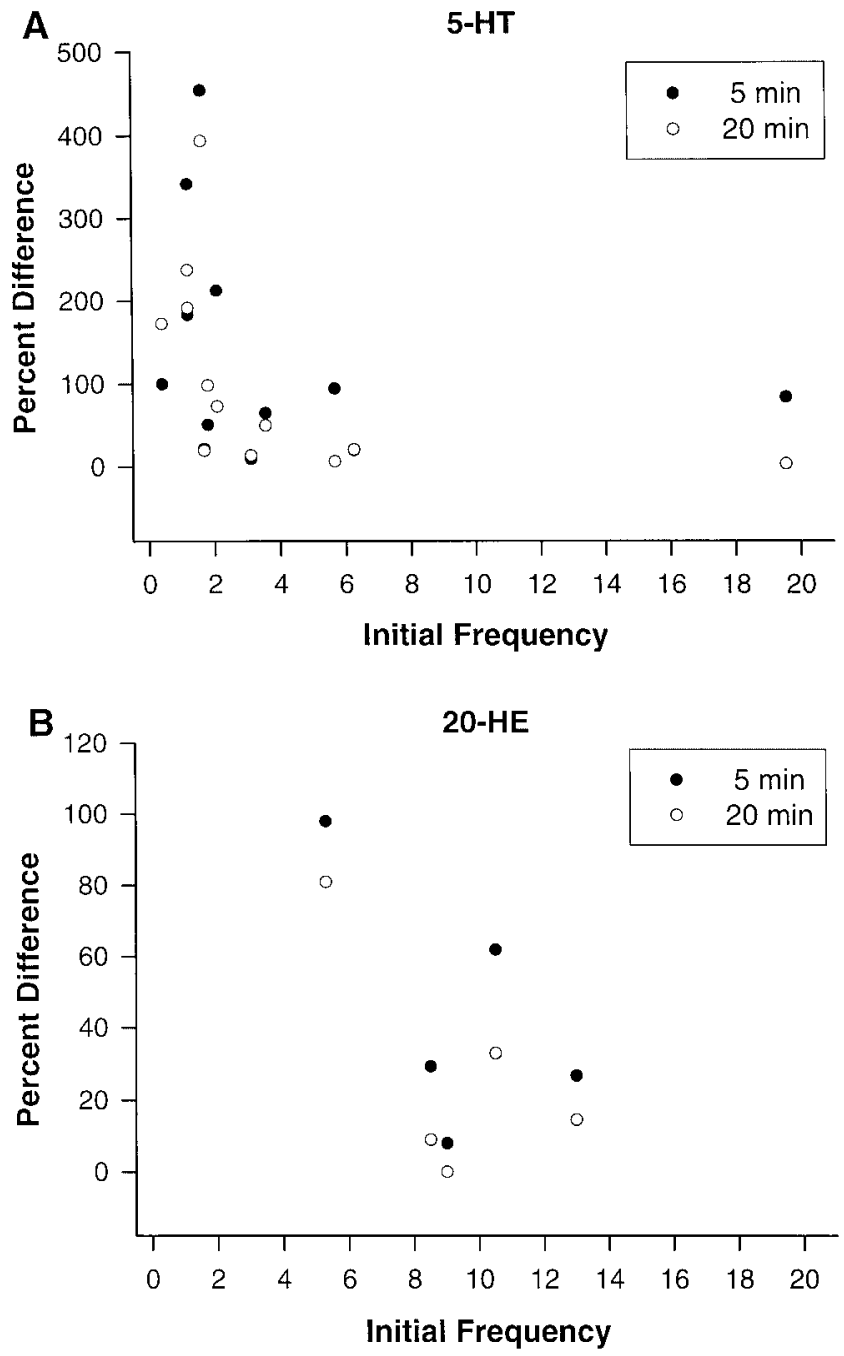

Fig. 5. The correlation of the percent difference and the initial firing frequency in response to 5 -HT or $20-\mathrm{HE}$. The percent difference in the responses at 5 and 20 minutes after application of the compounds are compared to the initial baseline firing frequency for both sets of 5-HT (A) and 20-HE (B).

an overall excitatory effect is observed (Fig. 6C). This suggests that the two compounds might be working through different mechanisms, such as second messenger cascades or direct actions on channels, in enhancing the cell's responsiveness to the given stimulus (i.e., maintained stretch).

A previous study by Pasztor and MacMillian (1990) showed the influence of 5-HT at $1 \mu \mathrm{M}$ on both the rapidly- and slowly-adapting MROs when the muscle was stretched with trapezoidal ramps. For comparative purposes, we also used $1 \mu \mathrm{M} 5$-HT, but in addition used lower concentrations (10 $\mathrm{nM}$ and $100 \mathrm{nM})$ to obtain a few dose-response curves for given preparations. Figure 7A shows a representative response to a $10-\mathrm{nM}$ 5 -HT exposure followed by a complete exchange of the bath with saline (few seconds) and then re-exposure to 5 -HT at $100 \mathrm{nM}$. Repeating the wash procedure and exposure to an even higher concentration of $1 \mu \mathrm{M}$ revealed that the initial response to 5 -HT is dose-depen- 


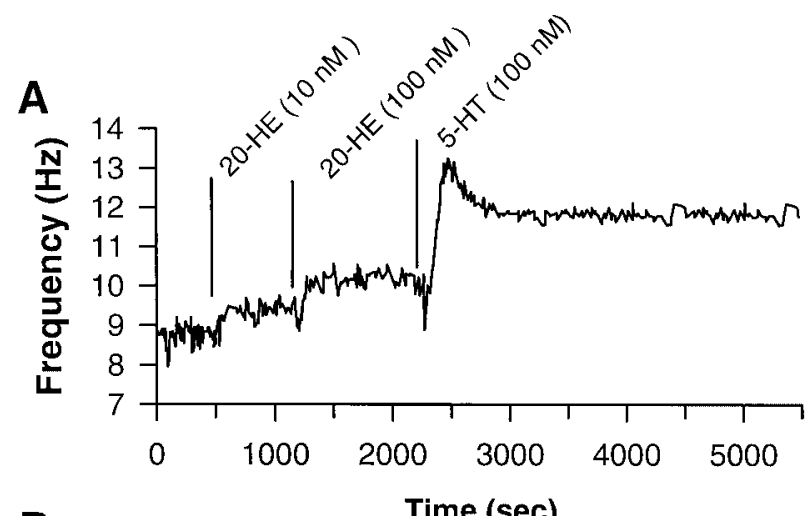

B
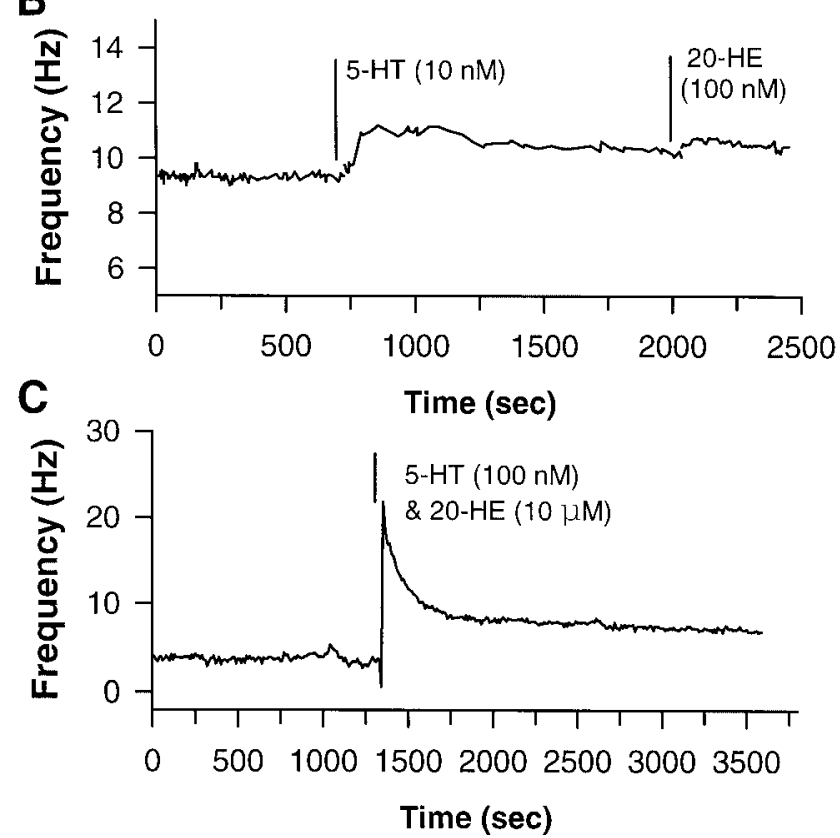

Fig. 6. The interactions of 5-HT and 20-HE. A: The firing frequency of the MRO still retains a substantial increase in the firing frequency when exposed to 5-HT even with a previous exposure to various concentrations of $20-\mathrm{HE}$ over tens of minutes. B: Likewise when the activity is already heightened by 5 -HT, an additional influence to 20-HE is still observed. C: Also, when the two compounds are mixed prior to application and then applied, there is an enhancement of activity.

dent. Note in this particular recording, the firing frequency initially dropped followed by a rapid rise upon switching the bathing medium to one containing $10 \mu \mathrm{M}$ 5 -HT. Obviously, the concentration and duration of exposure of each neuromodulator are important in determining how one compound acts on the other's response. Dose-dependence was not as clear for 20-HE because of the varied responses in activity even after exchanging the bathing medium three times in rapid secession with saline. A representative response to increasing concentrations of 20-HE exposure is shown in Figure 7B. In general, the higher the concentration of $20-\mathrm{HE}$, the greater the increase in the MRO activity as compared to initial saline exposure (Fig. 8), whereas the percent differences in response to 5 -HT appears to
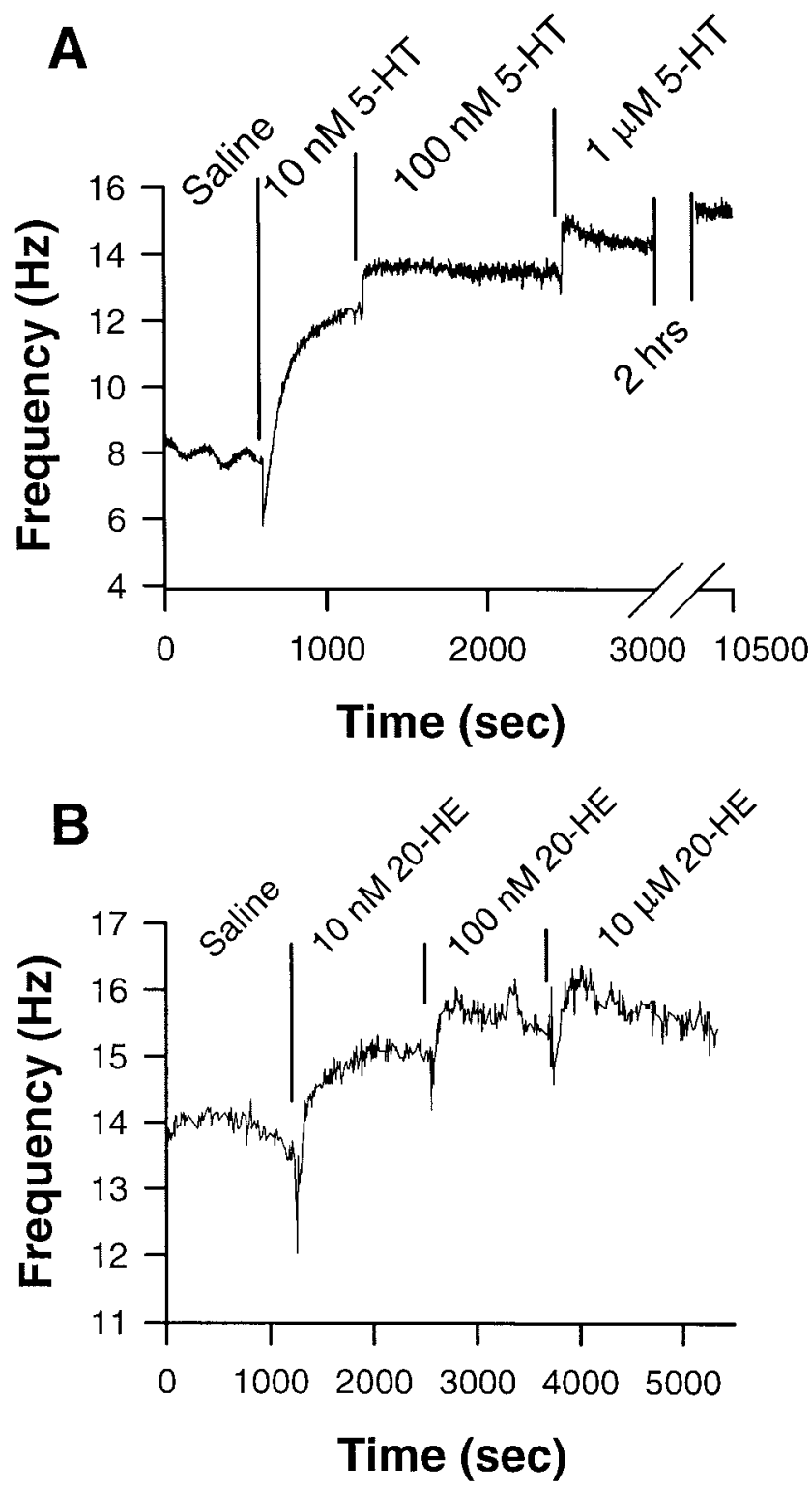

Fig. 7. Representative changes in the firing frequency to increasing concentrations of 5-HT or 20-HE. A: Sequential adding of 5-HT with increasing concentrations resulted in further enhancement of the firing frequency. With continual exposure to the high concentration $(1 \mu \mathrm{M})$ of 5 -HT, the high activity level lasted for more than 2 hours in this preparation. B: The firing frequency upon exposure to increasing concentrations of $20-\mathrm{HE}$ also showed an enhancement of activity with each increasing dose. However, the responses usually were not maintained at the increased level immediately following exposure.

plateau (Fig. 8). The mixed exposure of 5-HT (100 nM) and $20-\mathrm{HE}(10 \mu \mathrm{M})$ resulted in the percent difference in firing frequency greater than that for $10 \mu \mathrm{M} 20-\mathrm{HE}$ exposure and within the margin of observations for the 100 nM 5-HT (Fig. 8).

\section{Input Resistance and Resting Membrane Potential}

The amplitude of the receptor potential is related to the amount of net current and the cell's input resis- 

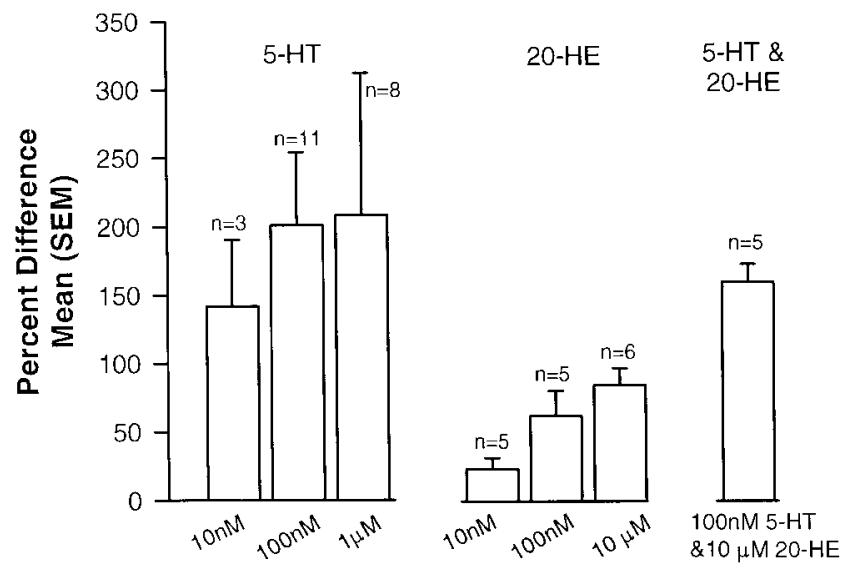

Fig. 8. Mean differences among various doses for each modulator individually and as a mixture. The percent difference for each preparation was used to obtain the mean and standard error of the mean (SEM) for each concentration used. All comparisons were made to baseline values in saline prior to modulatory exposure. The variation among the preparations is high because the initial firing frequencies were different among the preparations. The standard errors of the mean were not as large among the 20-HE experiments as compared to the 5-HT experiments because the overall changes were not as large. There is no significant difference between the responses for the cocktail of 5-HT and 20-HE to the 5-HT $(100 \mathrm{nM})$ alone exposure. The number of preparations is represented by "n."

tance $\left(R_{\text {in }}\right)$, both of which could possibly be influenced by 5 -HT and 20 -HE. In addition, the resting membrane potential $\left(\mathrm{V}_{\mathrm{m}}\right)$ could likely be altered by neuromodulators. These biophysical factors play significant roles in the excitability of the MRO sensory neurons.

To examine if 5-HT and/or $20-\mathrm{HE}$ altered the $\mathrm{R}_{\text {in }}$ or $\mathrm{V}_{\mathrm{m}}$, they were monitored in the absence of and during the exposure to each neuromodulator by intracellular recordings. The responses indicated that neither $R_{\text {in }}$ nor $\mathrm{V}_{\mathrm{m}}$ was altered significantly by exposure to 5 -HT at concentrations known to alter the firing frequencies as already shown in Figure 2. However, the neurons would spike at a lower amount of positive current injection when exposed to 5 -HT. This suggests that the threshold level for eliciting an action potential may be reduced with exposure to 5-HT (Fig. 9). Future experiments with voltage clamping the cell are needed to resolve this issue. The $R_{\text {in }}$ increased with $20-\mathrm{HE}$ exposure within the first 10 minutes after application, and the $R_{\text {in }}$ continued to increase for about 20 minutes at which time the effect plateaued to a steady state. The illustrated V/I curves reveals the type of change observed (Fig. 10).

\section{DISCUSSION}

In this study, we have illustrated that 5-HT and the molt-related hormone, 20-hydroxyecdysone (20-HE), increased the firing frequency of the slow-adapting muscle receptor organ (MRO) of the crayfish abdomen in the presence of a given static position. Concentrations from $10 \mathrm{nM}$ to $1 \mu \mathrm{M}$ for 5-HT and $10 \mathrm{nM}$ to $10 \mu \mathrm{M}$ for 20-HE were tested and all increased activity. A mixture of 5-HT and 20-HE also produced increased firing of the neuron. The rate in the rise of increased activity was relatively quick, from a few seconds to

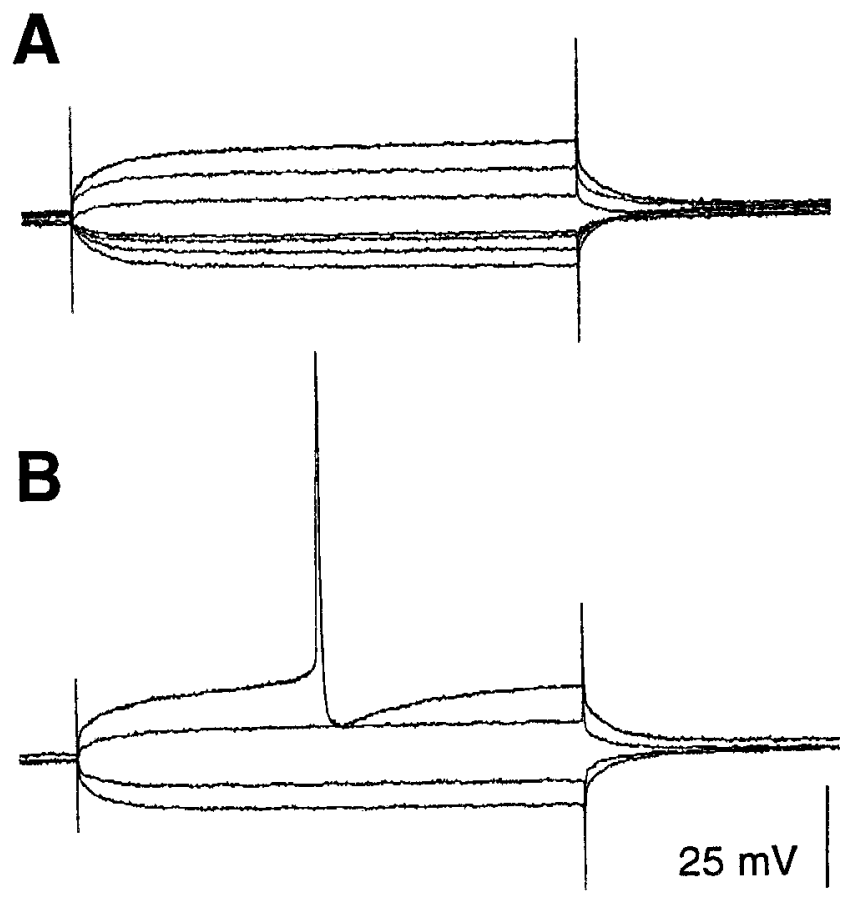

Fig. 9. Voltage measures during current injection before and during 5-HT application. Current steps $(+1.0,+1.8,+2.5,-1.0,-1.8$, -2.0 , and $-2.5 \mathrm{nA}$ ), shown in $\mathbf{A}$, were replicated after 5 minutes of continuous bathing in $100 \mathrm{nM} 5$-HT, but with 5-HT exposure the cell elicited an action potential at the $+1.8 \mathrm{nA}$ step. This trend was common among the preparations. Over 10 minutes of continuously bathing in 5-HT (100 nM), it appeared that the neuron displayed a lowered threshold over time while maintaining a constant resting membrane potential $(\mathbf{B})$. The current pulses were $160 \mathrm{msec}$ in duration.

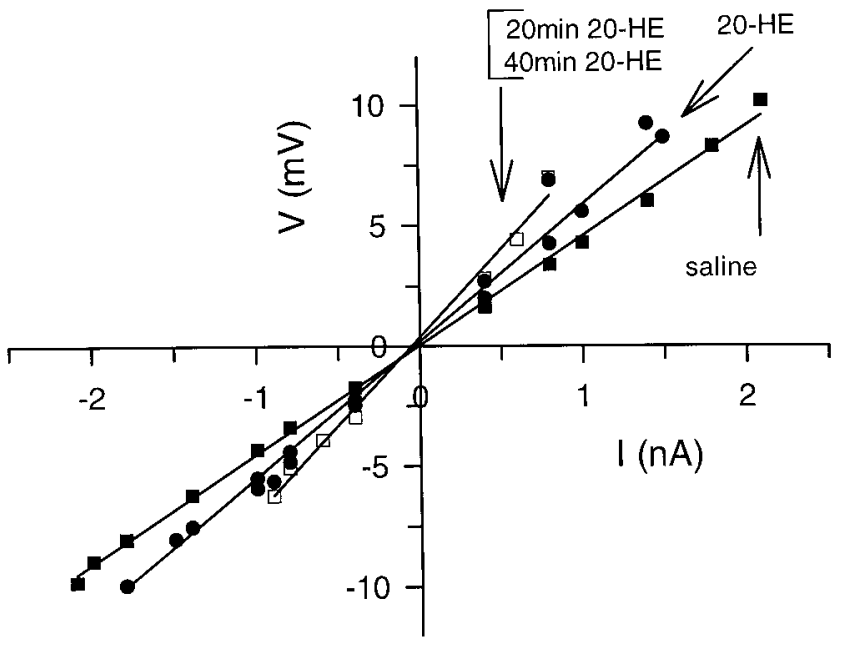

Fig. 10. Voltage/Current measures before and during 20-HE application. The application of $20-\mathrm{HE}(10 \mu \mathrm{M})$ resulted in the $\mathrm{V}$ curve increasing its slope over a 10-minute bathing period. With further time measures in obtaining relationships, it was noted that a 20 minute bathing time is sufficient for the effect to plateau since no further alteration was noted after 40 minutes. The closed squares are during saline exposure, the closed circles are during 20-HE exposure within 10 minutes, and the open squares represent the responses for 20 and 40 minutes of exposure. The lines represent a least squares fit to all points within a data set. 
minutes, as compared to the slow decay of the activity that occurred after several hours in the presence of the modulators. The variations in the rate of increase in firing frequency caused by the modulators might be related to the life history of the animals or variations within their molt cycle. How the modulators work together to alter the activity of this sensory neuron that monitors proprioceptive information in relation to the animal's behavior is of interest for future investigations.

When examining the influences of neuromodulators or other substances on the activity of the neuron, one has to consider the influences that these substances may have directly on the muscle fiber. If the tested substance increases tension of the muscle fiber, then it could increase impulse frequency without necessarily having a direct effect on the neuron. Since the single isolated muscle fiber is quite small, alterations in tension are not easily measured in the necessary sensitivity range; however, Pasztor and MacMillan (1990) reported that there was no change in muscle tension upon application of 5-HT using varied methods. This suggests that muscle contraction was not induced by 5-HT and that the heightened sensory activity in the slow adapting neuron is a result of direct actions on the neuron. However, in the intact animal, 5-HT would affect evoked transmitter release from motor nerve terminals as well as have direct effects on the sensory neuron. Thus, 5-HT would probably heighten activity within the entire neural circuit related to the MRO. In fact, 5-HT may very likely have an effect in enhancing the spontaneous release of vesicles from both the excitatory and inhibitory motor neurons as is known to be the case for other motor nerve terminals within crustaceans (Finger and Martin, 1986; Fischer and Florey, 1982; Florey and Rathmayer, 1978).

The rate of adaptation, in the presence of physiological saline, between the rapidly- and slowly-adapting MROs has previously been examined in detail. Adaptation in the slow-adapting MRO appears to be mostly related to the decay in the receptor current (Purali, 1997), and also in part due to the activity of the $\mathrm{Na}^{+}-\mathrm{K}^{+}$pump (Nakajima and Onodera, 1969a; Nakajima and Takahashi, 1966). We do not know if 5-HT or 20-HE alters either the receptor current or the pump activity from the studies we presented.

In considering the possible underlying mechanisms that could cause enhanced excitability of the sensory neuron by 5 -HT, it is possible that there is an increase in the input resistance of the neuron so that a given current would produce a larger potential. This would make the threshold more easily attainable. In neurons from the antennal lobes of Manduca sexta, 5-HT caused an increase in the cell's input resistance and broadened its action potential, resulting in an increased overall excitability (Mercer et al., 1996). The results of examining input resistance as measured with current injections showed that 5-HT did not consistently alter $R_{\text {in }}$, but that $20-\mathrm{HE}$ caused $\mathrm{R}_{\text {in }}$ to increase. It appears that the potential of the cell membrane when the neuron is at rest remains unaltered by $5-\mathrm{HT}$ and $20-\mathrm{HE}$ after the first few minutes of application. At the skeletal neuromuscular junctions, 5-HT's cellular actions arise due to activation of the $\mathrm{IP}_{3}$ and cAMP second-messenger systems (Dixon and Atwood, 1989), which then have an effect on proteins associated with vesicular release ( $\mathrm{He}$ et al., 1999; Southard et al., 2000).

It is harder to speculate about 20-HE's actions since the non-genomic receptors for ecdysone are not identified. Since the effects of 20-HE appear to be relatively rapid, as compared to typical genomic effects of steroids, it is likely that it affects either the ion channels directly or some biophysical aspect associated with the membrane. In crayfish and Drosophila, 20-HE acts on the presynaptic terminal in neuromuscular junctions (Cooper and Ruffner, 1998; Li et al., 2001; Li and Cooper, 2001; Ruffner et al., 1999). It depressed synaptic transmission, but the depression could be overridden by the presence of 5-HT for crayfish NMJs. So, we also wanted to know if the steroid, 20-HE, had a depressive action on primary sensory neurons, and if such an effect could also be altered by the presence of 5-HT at the neuromuscular junctions. Although exposure of the opener motor nerve terminals to 20-HE decreased the number of vesicles released for each evoked response, it excited MRO activity in the absence of evoked motor nerve activity to the receptor organ muscle.

Since it is well established that numerous neuromodulators are present in the crayfish hemolymph, it is very likely that not just one neuromodulator is responsible for a behavioral state, but that cocktails control behavioral states of the whole animal. Recently, it was shown that the neuromodulator octopamine antagonizes 5-HT's effects of enhancing synaptic transmission (Djokaj et al, 2001). In addition, variations in responsiveness to exogenous application of neuromodulators between preparations may well be related to the prior life history of the animal. It is known that receptors to hormones or neuromodulators undergo up- and downregulation via alteration of their expression levels and/or densities on cell surfaces (Azaryan et al., 1998). Pharmacological action of agonists or antagonists binding to a receptor can regulate its functional levels (Fone et al., 1998; Kokay and Mercer, 1997; Welner et al., 1989). For example, it has been shown that $5-\mathrm{HT}_{1 \mathrm{~A}}$ receptors will be desensitized when either an agonist or antagonist is present (Hensler and Truett, 1998). In our laboratory, we have shown alterations in the physiological sensitivity to exogenous application of 5-HT at the crayfish neuromuscular junctions after altering levels of endogenous 5-HT as well as for chronic exposure of a 5-HT agonist (Cooper et al., 2001). This is important since it is thought that the levels of 5-HT as well as other neuromodulators might be related to various social states in crustaceans (Sneddon et al., 2000).

Understanding the behavior of the whole animal at various stages of its life when neuromodulators and hormones are varying will provide a better holistic view of the biological system. Such neuromodulators and hormonal changes in crustaceans when they are either developing or maintaining a social status may have prolonged effects on the nervous system and behavior. The place in the social hierarchy or behavioral changes over a molt cycle may possibly be related to levels to hormones but this has not been fully established yet.

Here we have presented the effects of neuromodulators during maintained sensory activity to simulate a crayfish in aggressive and submissive postures with its abdomen in a steady position (extended or flexed). Fur- 
ther investigations on sensory neurons could relate the mechanisms of neuromodulators to those known at neuromuscular junctions with varying synaptic efficacy (Atwood and Cooper 1995, 1996; LaFramboise et al., 2000). Recently, we have been addressing the influence of these neuromodulators on motor nerve terminals (Crider and Cooper, 1999, 2000; Griffis et al., 2000; He et al., 1999; Southard et al., 2000) and central integration of sensory input (Strawn et al., 2000).

Future investigations related to neuromodulation of the MRO as a whole need to address several issues: (1) 5-HT receptor subtypes, distribution, and density; (2) the influence of neuromodulators on synaptic efficacy of the motor nerves associated with the muscles that comprise the MROs as well as the input directly on the sensory cells; (3) the possible influence of 5-HT and $20-\mathrm{HE}$ in altering the threshold for inducing an action potential via actions on ion channel conductance as measured with voltage-clamp procedures; and (4) the animal's sense of proprioception under the influence of neuromodulators on primary sensory neurons and central integration of their signals.

\section{ACKNOWLEDGMENTS}

Illustrations were provided courtesy of Hye Won Cooper. In addition, we thank Brian Mulloney (Univ. of Davis, CA) for comments and suggestions, Austin M. Cooper for editorial assistance, and Kenneth Lachnicht for scientific style editing. Funding was provided by Howard Hughes Medical Institute undergraduate training fellowships (E.W. and W.M.W.), NIHNIGMS-GM 55275 Multi-Level Minority Research Development Plan (to Donald T. Frazier, Univ. of Kentucky for R.B.), and in part by NSF grants IBN9808631 and ILI DUE-9850907 (R.L.C.).

\section{REFERENCES}

Alexandrowicz JS 1951. Muscle receptor organs in the abdomen of Homarus vulgaris and Palinurus vulgaris. Q J Microsc Sci 92:163199.

Atwood HL, Cooper RL. 1995. Functional and structural parallels in crustaceans and Drosophila neuromuscular systems. Am Zool 35: $556-565$

Atwood HL, Cooper R.L. 1996. Synaptic diversity and differentiation: Crustacean neuromuscular junctions. Invertebr Neurosci 1:291307.

Azaryan AV, Clock BJ, Rosenberger JG, Cox BM. 1998. Transient up regulation of mu opioid receptor mRNA levels in nucleus accumbens during chronic cocaine administration. Can J Physiol Pharmacol $76: 278-283$.

Brown HM, Ottoson D, Rydqvist B. 1978. Crayfish stretch receptor: An investigation with voltage-clamp and ion-sensitive electrodes. J Physiol 284:155-179.

Bush BMH, Laverack MS. 1982. Mechanoreception. In: Atwood HL, Sandeman DC, editors. The biology of crustacea. neurobiology: structure and function, Vol. 3. New York: Academic Press. p 399468

Cameron JN. 1989. Post-moult calcification in the blue crab, Callinectes sapidus: Timing and mechanism. J Exp Biol 143:285-304.

Cases O, Seif I, Grimsby J, Gaspar P, Chen K, Pournin S, Muller U, Aguet M, Babinet C, Shih JC, De Maeyer E. 1995. Aggressive behavior and altered amounts of brain serotonin and norepinephrine in mice lacking MAOA. Science 268:1763-1766.

Coccaro EF. 1992. Impulsive aggression and central serotonergic system function in humans: an example of a dimensional brain-behavior relationship. Intern Clin Psychopharmacol 7:3-12.

Cooke IM, Sullivan RE. 1982. Hormones and neurosecretion. In: Bliss DE, editor. The biology of crustacean neurobiology: structure and function. Vol. 3. New York: Academic Press. p 206-290.

Cooper RL, Ruffner ME. 1998. Depression of synaptic efficacy at intermolt in crayfish neuromuscular junctions by 20 -Hydroxyecdysone, a molting hormone. J Neurophysiol 79:1931-1941.
Cooper RL, Tabor J, Chase RJ. 2001. Altered responsiveness to 5-HT at the crayfish neuromuscular junction due to chronic p-CPA \& m-CPP treatments. Brain Res 916:143-51.

Crider ME, Cooper RL. 1999. The importance of the stimulation paradigm in determining facilitation and effects of neuromodulation. Brain Res 842:324-331.

Crider ME, Cooper RL. 2000. Differentially facilitation of high- and low-output nerve terminals from a single motor neuron. J Appl Physiol 88:987-996.

Cromarty SI, Mello J, Kass-Simon G. 1998. Behavioral analysis of escape behavior in male, and gravid and non-gravid, female lobsters. Biol Bull 194:63-71.

Dixon D, Atwood HL. 1989. Conjoint action of phosphoinositol and adenylate cyclase systems in serotonin-induced facilitation at the crayfish neuromuscular junction. J Neurophysiol 62:1251-1259.

Djokaj S, Cooper RL, Rathmayer W. 2001. Effects of octopamine, serotonin, and cocktails of the two modulators on synaptic transmission at crustacean neuromuscular junctions. J Comp Physiol A 187:145-154.

Doernberg SB, Cromarty SI, Heinrich R, Beltz BS, Kravitz EA. 2001. Agonistic behavior in naive juvenile lobsters depleted of serotonin by 5,7-dihydroxytryptamine. J Comp Physiol A 187:91-103.

Eckert RO. 1961a. Reflex relationships of the abdominal stretch receptors of the crayfish. I. Feedback inhibition of the receptors. J Cell Comp Physiol 57:149-162.

Eckert RO. 1961b. Reflex relationships of the abdominal stretch receptors of the crayfish. II. Stretch receptor involvement during the swimming reflex. J Cellular Comp Physiol 57:163-174.

Edwards C, Ottoson D, Rydqvist B, Swerup C. 1981. The permeability of the transducer membrane of the crayfish stretch receptor to calcium and other divalent cations. Neuroscience 6:1455-1460.

Elekes K, Florey E. 1987a. New types of synaptic connections in crayfish stretch receptor organs: an electron microscopic study. J Neurocytol 16:613-26.

Elekes K, Florey E. 1987b. Immunocytochemical evidence for the GABAergic innervation of the stretch receptor nerons in crayfish. Neuroscience 22:1111-1122.

Erxleben C. 1989. Stretch-activated current through single ion channles in the abdominal stretch receptor organ of the crayfish. J Gen Physiol 94:1071-1083.

Eyzaguirre C, Kuffler SW. 1955 Processes of excitation in the dendrites and in the soma of single sensory nerve cells of the lobster and crayfish. J Gen Physiol 39:87-119.

Fields HL. 1976. Crustacean abdominal and thoracic muscle receptor organs. In: Mill PJ, editor. Structure and function of proprioceptors in the invertebrated. New York: Chapman \& Hall. p 65-114.

Finger W, Martin C. 1986. Spontaneous excitatory postsynaptic currents in crayfish neuromuscular junctions in the absence and presence of serotonin and 3,4-diaminopyridine. J Comp Physiol A 159: 13-20.

Fischer L, Florey E. 1982. Modulation of synaptic transmission and excitation-contraction coupling in the opener muscle of the crayfish, Astacus leptodactylus, by 5-hydro-xytryptamine and octopamine. J Exp Biol 102:187-198.

Florey E, Florey E. 1955. Microanatomy of the abdominal stretch receptors of the crayfish Astacus fluviatilis L. J Gen Physiol 39:6985.

Florey E, Rathmayer M. 1978. The effects of octopamine and other amines on the heart and on the neuromuscular transmission in decapod crustaceans: further evidence for a role as a neurohormone. Comp Biochem Physiol 61C: 229-237.

Fone KC, Austin RH, Topham IA, Kennett GA, Punhani T. 1998. Effect of chronic m-CPP on locomotion, hypophagia, plasma corticosterone and 5-HT2C receptor levels in the rat. Br J Pharmacol 123:1707-1715.

Griffis B, Bonner P, Cooper RL. 2000 Sensitivity of transformed (phasic to tonic) motor neurons to the neuromodulator 5-HT. Comp Biochem Physiol A 127:495-504.

Guillemin R. 1978. Peptides in the brain. Science 202:390-402.

He P, Southard RC, Whiteheart SW, Cooper RL. 1999. Role of $\alpha$-SNAP in promoting efficient neurotransmission at the crayfish neuromuscular junction. J Neurophysiol 82:3406-3416.

Hensler JG, Truett KA. 1998. Effect of chronic serotonin-2 receptor agonist or antagonist administration on serotonin-1A receptor sensitivity. Neuropsychopharmacol 19:354-64.

Huber R, Delago A. 1998. Serotonin alters decisions to withdraw in fighting crayfish, Astacus astacus: the motivational concept revisited. J Comp Physiol 182:573-583.

Huber R, Orzeszyna M, Pokorny N, Kravitz EA. 1997a. Biogenic amines and aggression: experimental approaches in crustaceans. Brain Behav Evol 50:60-68. 
Huber R, Smith K, Delago A, Isaksson K, Kravitz EA. 1997b. Serotonin and aggressive motivation in crustaceans: altering the decision to retreat. PNAS 94:5939-5942.

Hunt CC, Wilkerson, RS, Fukami Y. 1978. Ionic basis of the receptor potential in primary endings of mammalian muscle spindles. J Gen Physiol 71:683-698.

Jan LY, Jan YN. 1982. Peptidergic neurotransmission in the sympathetic ganglion of the frog. J Physiol 327:219-246.

Kokay IC, Mercer AR. 1997. Age-related changes in dopamine receptor densities in the brain of the honey bee, Apis mellifera. J Comp Biochem 181:415-423.

Kravitz EA, Glusman S, Harris-Warrick RM, Livingstone MS, Schwarz T, Goy MF. 1980. Amines and a peptide as neurohormones in lobsters: actions on neuromuscular preparations and preliminary behavioral studies. J Exp Biol 89:159-175.

Kuffler SW. 1954. Mechanisms of activation and motor control of stretch receptors in lobster and crayfish. J Neurophysiol 17:558574.

Kuffler SW, Eyzaguirre C. 1955. Synaptic inhibition in an isolated nerve cell. J Gen Physiol 39:155-184.

LaFramboise W, Griffis B, Bonner P, Warren W, Scalise D, Guthrie RD, Cooper RL. 2000. Muscle type-specific myosin isoforms in crustacean muscles. J Exp Zool 286:36-48.

Li H, Cooper RL. 2001. Maintaining synaptic efficacy at the neuromuscular junction in Drosophila larva during normal development and prolonged life with the ecdysoneless mutant. Neuroscience 106:193-200.

Li H, Ward E, Bradacs H, Cooper RL. 1997. Neuromodulator effects on primary sensory neurons: rapidly and slowly adapting proprioceptors. Abstr Soc Neurosci 313:8.

Li H, Harrison D, Jones G, Jones D, Cooper RL. 2001. Alterations in development, behavior, and physiology in Drosophila larva that have reduced ecdysone production. J Neurophysiol 85:98-104.

Linnoilia VM, Virkkunen M. 1992. Aggression, suicidality, and serotonin. J Clin Psychiatry 53:46-51.

Livingstone MS, Harris-Warrick RM, Kravitz EA. Serotonin and octopamine produce opposite postures in lobsters. Science 208:76-79.

McCarthy BJ, MacMillian DL. 1995. the role of the muscle receptor organ in the control of the abdominal extension in the crayfish Cherax destructor. J Exp Biol 198:2253-2259.

Mercer AR, Kloppenburg P, Hildebrand JG. 1996. Serotonin-induced changes in the excitability of cultured antennal-lobe neurons of the sphinx moth Manduca sexta. J Comp Physiol A 178:21-31.

Moffet SB. 1975. Motor patterns and structural interactions of basiischiopodite levator muscles in routine limb elevation and production of autotomy in the land crab, Cardisoma guanhumi. J Comp Physiol 96:285-305.

Nakajima Y, Onodera K. 1969a. Membrane properties of the stretch receptor neurons of crayfish with particular reference to mechanisms of sensory adaptation. J Physiol 200:161-185.

Nakajima Y, Onodera K. 1969b. Adaptation of the generator potential in the crayfish stretch receptors under constant tension. J Physiol 200:187-204.

Nakajima Y, Takahashi K. 1966. Post-tetanic hyperpolarization and electrogenic $\mathrm{Na}$ pump in stretch receptor neurone of crayfish. J Physiol 187:105-127.
Nusbaum MP, Marder E. 1989. A modulatory proctolin-containing neuron (MPN). II. State-dependent modulation of rhythmic motor activity. J Neurosci 9:1600-1607.

O'Shea M, Schaffer M. 1986. Neuropeptide function: The invertebrate contribution. Ann Rev Neurosci 8:171-198.

Pasztor VM, MacMillan DL. 1990. The actions of proctolin, octopamine and serotonin on the crustcean proprioceptors show species and neurone specificity. J Exp Biol 152:485-504.

Purali N. 1997. Mechanisms of adaptation in a mechanoreceptor. A study of mechanical and ionic factors in the crayfish stretch receptors. PhD dissertation, Department of Physiology and Pharmacology, Karolinska Institutet, Stockholm, Sweden.

Purali N, Rydqvist B. 1992. Block of potassium outward currents in the crayfish stretch receptor neurons by 4-aminopyridine, tetraethylammonium chloride and some other chemical substances. Acta Physiol Scand 146:67-77.

Ruffner ME, Cromarty SI, Cooper RL. 1999. Depression of synaptic efficacy in Drosophila neuromuscular junctions by the molting hormone (20-HE). J Neurophysiol 81:788-794.

Rydqvist B, Purali N. 1991. Potential-dependent potassium currents in the rapidly adapting stretch receptor neuron of the crayfish. Acta Physiol Scand 142:67-76.

Rydqvist B, Swerup C. 1991.Stimulus-response properties of the slowly adapting stretch receptor neuron of the crayfish. Acta Physiol Scand 143:11-19.

Segraves WA. 1994. Steroid receptors and other transcription factors in ecdysone response. Recent Prog Hormone Res 49:167-195.

Sneddon LU, Taylor AC, Huntingford FA, Watson DG. 2000 Agonistic behavior and biogenic amines in shore crabs Carcinus maenas. J Exp Biol 203:537-545.

Sohn J, Mykles DL, Cooper RL. 2000. The anatomical, physiological and biochemical characterization of muscles associated with the articulating membrang in the dorsal surface of the crayfish abdomen. J Exp Znol 287:253-377.

Southard RC, Haggard J, Crider ME, Whiteheart SW, Cooper RL. 2000. Influence of serotonin on the kinetics of vesicular release. Brain Res 871:16-28.

Strawn JR, Neckameyer WS, Cooper RL, 2000. The effects of 5-HT on sensory, central and motor neurons driving the abdominal-superficial flexor muscles in the crayfish. Comp Biochem Physiol 127B 523-550.

Swerup C, Rydqvist B. 1992. The abdominal stretch receptor organ of the crayfish. Comp Biochem Physiol A 103:433-431.

Truman HW, Reiss SW. 1995. Neuromuscular metamorphosis in the moth Manduca sexta: Hormonal regulation of synapse loss and remodeling. J Neurosci 15:4814-4826.

von Richter K. 1979. Zur wirkung von ecdysteron auf eine periphere motorische nervenaktivität bei der schabe Periplaneta americana L. Zool Jb Physiol 83:350-360.

Welner SA, De Montigny C. Desroches J, Ddjardins P, SuranyiCadotte BE. 1989. Autoradiographic quantification of serotonin 1A receptors in rat brain following antidepressant drug treatment. Synapse 4:247-352.

Winberg S, Nisson GE, Olsen KH. 1992. Changes in brain serotonergic activity during hierarchic behavior in Arctic charr (Salvelinus alpinus L.) are socially induced. J Comp Physiol A 170:93-99. 